\title{
D-dimer is Associated with Severity of Coronavirus Disease 2019: A Pooled Analysis
}

\author{
Giuseppe Lippi ${ }^{1} \quad$ Emmanuel J. Favaloro ${ }^{2}$ \\ ${ }^{1}$ Section of Clinical Biochemistry, Department of Neuroscience, \\ Biomedicine and Movement, University of Verona, Verona, Italy \\ ${ }^{2}$ Department of Haematology, Sydney Centres for Thrombosis and \\ Haemostasis, Institute of Clinical Pathology and Medical Research, \\ NSW Health Pathology, Westmead Hospital, Westmead, New South \\ Wales, Australia
}

Thromb Haemost 2020;120:876-878.

A new infective outbreak, sustained by severe acute respiratory syndrome coronavirus 2 (SARS-CoV-2) and defined coronavirus disease 2019 (COVID-19), is now spreading all around the world. ${ }^{1}$ The clinical course of this respiratory disease is complicated in up to $15 \%$ of infected patients by onset of interstitial pneumonia, evolving toward acute respiratory distress syndrome needing mechanical ventilation or admission to the intensive care unit (ICU), and is also often accompanied by multiorgan failure. ${ }^{2}$ Since there is now incontrovertible evidence that laboratory hemostasis provides an essential contribution to decision-making and care of the vast majority of human pathologies, ${ }^{3}$ we aimed to explore here whether increased D-dimer values-which are a frequent occurrence in patients with COVID- $19^{4}-$ may be associated with disease severity.

An electronic search was performed in Medline (PubMed interface), Scopus, and Web of Science, using the keywords "laboratory" and "COVID-19" or "coronavirus 2019" or "2019nCoV" or "SARS-CoV-2," between 2019 and present time (i.e., March 4, 2020), with no language restriction. The title, abstract, and full text of all documents that could be identified based on these search criteria were analyzed, and those reporting information on the difference of D-dimer values between COVID-19 patients with or without severe disease (i.e., those needing mechanical ventilation, ICU admission, or those who died) were finally included in our analysis. The reference list of each identified document was also examined for identifying additional eligible studies. A pooled analysis was finally performed, with calculation of weighted mean difference (WMD) and 95\% confidence interval (CI) of D-dimer values between COVID-19 patients with or without severe disease, using MetaXL software Version 5.3 (EpiGear International Pty Ltd., Sunrise Beach, Australia). Mean and standard deviation were extrapolated from sample size, median, and interquartile range (IQR),

received

March 4, 2020

accepted after revision

March 12, 2020

Address for correspondence Giuseppe Lippi, MD, Section of Clinical Biochemistry, University Hospital of Verona, Piazzale LA Scuro, 37134 Verona, Italy (e-mail: giuseppe.lippi@univr.it).

according to Hozo et al. ${ }^{5}$ The study was performed in accordance with the Declaration of Helsinki and with the term of local legislation.

Overall, 80 documents could be initially identified based on our search criteria, 77 of which ought to be excluded after title, abstract, or full text reading; since they were review articles $(n=6)$, commentaries, or other editorial material $(n=1)$, they did not deal with COVID-19 disease $(n=62)$, or did not expressly reported the difference of D-dimer values in COVID-19 patients with or without severe disease $(n=8)$. One additional study could be identified from the reference list of selected articles and another one was published while the article was under revision so that a total number of five studies could finally be included in our analysis. ${ }^{6-10}$ Four of these five studies reported median and IQR values of D-dimer, ${ }^{6-9}$ while the remaining only showed the proportion of patients with $D$ dimer values above the locally defined diagnostic cut-off. ${ }^{9}$

In the first study, Huang et al reported clinical and laboratory data of 41 patients hospitalized with laboratory-confirmed COVID- $19^{6}$ and observed that D-dimer values were nearly fivefold higher in those with severe disease (median: $2.4 \mathrm{mg} / \mathrm{L} ; \mathrm{IQR}: 0.6-14.4 \mathrm{mg} / \mathrm{L}$ ) than in those without (median: $0.5 \mathrm{mg} / \mathrm{L} ; \mathrm{IQR}: 0.3-0.8 \mathrm{mg} / \mathrm{L} ; \boldsymbol{p}=0.004$ ). Tang et al also studied 183 patients with COVID- $19^{7}$ and found that D-dimer values were nearly 3.5 -fold higher in those with severe disease (median: $2.12 \mathrm{mg} / \mathrm{L}$; IQR: $0.77-5.27 \mathrm{mg} / \mathrm{L}$ ) than in those without (median: $0.61 \mathrm{mg} / \mathrm{L} ; \mathrm{IQR}: 0.35-1.29 \mathrm{mg} / \mathrm{L} ; \boldsymbol{p}<0.001$ ). In the third study, published by Wang et al and including 138 patients hospitalized for COVID-19, ${ }^{8}$ D-dimer values were nearly 2.5 -fold higher in patients with severe disease (median: $4.14 \mathrm{mg} / \mathrm{L}$; IQR: $1.91-13.2 \mathrm{mg} / \mathrm{L}$ ) than in those without (median: $1.66 \mathrm{mg} / \mathrm{L} ; \mathrm{IQR}: 1.01-2.85 \mathrm{mg} / \mathrm{L} ; \boldsymbol{p}<0.001)$. In the third study, Zhou et al studied 191 patients with COVID- $19^{9}$ and found that D-dimer values were nearly ninefold higher in

(c) 2020 Georg Thieme Verlag KG Stuttgart · New York
DOI https://doi.org/ 10.1055/s-0040-1709650. ISSN 0340-6245. 


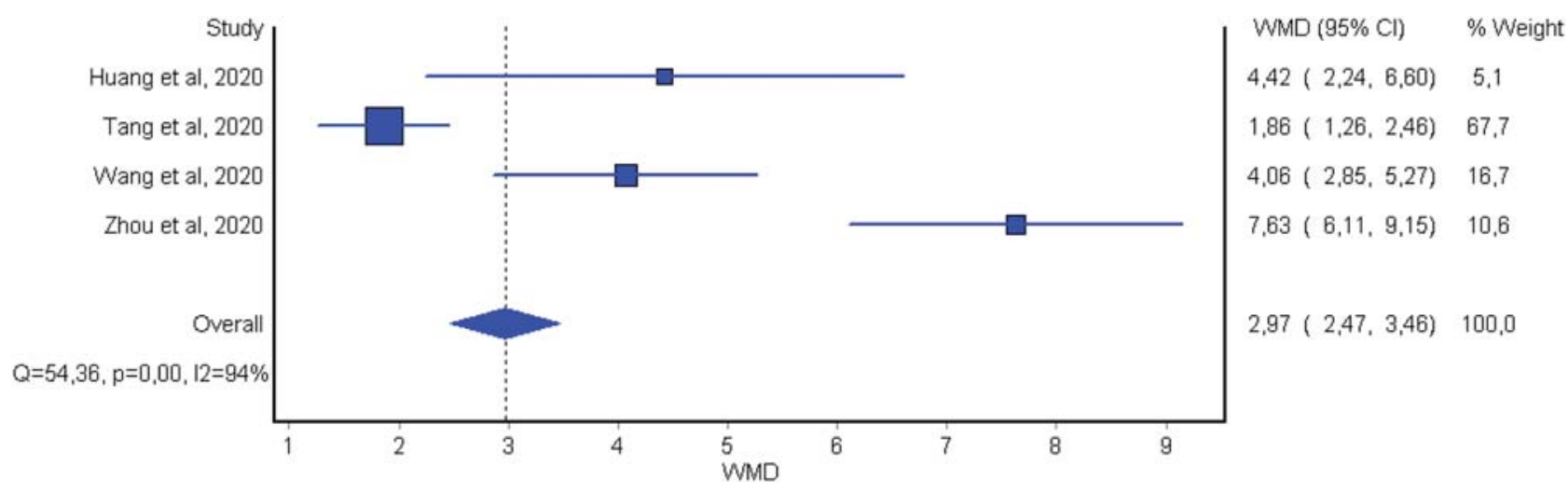

Fig. 1 Weighted mean difference and 95\% confidence interval of D-dimer values between patients with or without severe form of coronavirus disease 2019.

patients who died (median: $5.2 \mathrm{mg} / \mathrm{L}$; IQR: $1.5-21.1 \mathrm{mg} / \mathrm{L}$ ) than in those who survived (median: $0.6 \mathrm{mg} / \mathrm{L} ; \mathrm{IQR}: 0.3-1.0$ $\mathrm{mg} / \mathrm{L} ; \boldsymbol{p}<0.001$ ). In the study of Guan et al, who extracted data on 1,099 patients with laboratory-confirmed COVID-19 infection from 552 hospitals located in 30 Chinese territories, the risk of having D-dimer values above the locally defined cut-off (i.e., $\geq 0.5 \mathrm{mg} / \mathrm{L}$ ) was more frequent in patients with severe disease (65/109, i.e., 59.6\%) than in those without (195/451, i.e., $43.2 \% ; p=0.002$ ). The WMD of the four studies which reported continuous values (totaling 553 patients, 22\% with severe disease $)^{6-9}$ is summarized in - Fig. 1, showing that Ddimer values are considerably higher in COVID-19 patients with severe disease than in those without (WMD: $2.97 \mathrm{mg} / \mathrm{L}$; $95 \%$ CI: $2.47-3.46 \mathrm{mg} / \mathrm{L}$ ). The heterogeneity across the studies was found to be relatively high (i.e., $I^{2}, 94 \% ; p<0.001$ ).

Recent literature data show that D-dimer values are frequently enhanced in patients with COVID-19, being variably observed in 36 to $43 \%$ of positive cases. ${ }^{4}$ Nonetheless, what clearly emerges from the results of our pooled analysis is that D-dimer values are even higher in patients with severe COVID19 than in those with milder forms and therefore, D-dimer measurement may be associated with evolution toward worse clinical picture, though serial measurement would not be easily feasible at present in COVID-19 patients. Notably, Tang et al also recently highlighted that the vast majority of COVID-19 patients who died during hospital stay fulfilled the criteria for diagnosing disseminated intravascular coagulation (71.6 vs. $0.6 \%$ in survivors). ${ }^{7}$ Although D-dimer elevations recognize multifactorial etiology, our findings would lead us to conclude that D-dimer elevations and disseminated coagulopathy may be commonplace in patients with severe forms of COVID-19 as in other severe infections disease such as systemic human immunodeficiency virus, ${ }^{11}$ Ebola $^{12}$ and Zica, and Chikungunya virus ${ }^{13}$ so that urgent studies shall be planned to define whether adjunctive antithrombotic therapies (e.g., anticoagulants, antithrombin or thrombomodulin) may be helpful in patients with severe COVID-19.
Conflict of Interest

None declared.

\section{References}

1 World Health Organization. Coronavirus disease 2019 (COVID19) Situation Report - 43. Available at: https://www.who.int/emergencies/diseases/novel-coronavirus-2019/situationreports/. Accessed March 4, 2020

2 Mattiuzzi C, Lippi G. Which lessons shall we learn from the 2019 novel coronavirus outbreak? Ann Transl Med 2020;8(03):48

3 Lippi G, Favaloro EJ. Laboratory hemostasis: from biology to the bench. Clin Chem Lab Med 2018;56(07):1035-1045

4 Lippi G, Plebani M. Laboratory abnormalities in patients with COVID-2019 infection. Clin Chem Lab Med 2020. Doi: 10.1515/ cclm-2020-0198

5 Hozo SP, Djulbegovic B, Hozo I. Estimating the mean and variance from the median, range, and the size of a sample. BMC Med Res Methodol 2005;5:13

6 Huang C, Wang Y, Li X, et al. Clinical features of patients infected with 2019 novel coronavirus in Wuhan, China. Lancet 2020;395 (10223):497-506

7 Tang N, Li D, Wang X, Sun Z. Abnormal coagulation parameters are associated with poor prognosis in patients with novel coronavirus pneumonia. J Thromb Haemost 2020. Doi: 10.1111/jth.14768

8 Wang D, Hu B, Hu C, et al. Clinical characteristics of 138 hospitalized patients with 2019 novel coronavirus-infected pneumonia in Wuhan, China. JAMA 2020. Doi: 10.1001/jama.2020.1585

9 Zhou F, Yu T, Du R, et al. Clinical course and risk factors for mortality of adult inpatients with COVID-19 in Wuhan, China: a retrospective cohort study. Lancet 2020:S0140-6736(20)30566-3

10 Guan WJ, Ni ZY, Hu Y, et al; China Medical Treatment Expert Group for Covid-19. Clinical characteristics of coronavirus disease 2019 in China. N Engl J Med 2020. Doi: 10.1056/NEJMoa2002032

11 Borges AH, O'Connor JL, Phillips AN, et al; INSIGHT SMART Study Group; ESPRIT Study Group; SILCAAT Scientific Committee. Factors associated with D-dimer levels in HIV-infected individuals. PLoS One 2014;9(03):e90978

12 Ramacciotti E, Agati LB, Aguiar VCR, et al. Zika and chikungunya virus and risk for venous thromboembolism. Clin Appl Thromb Hemost 2019;25;. Doi: 10.1177/1076029618821184

13 Smither SJ, O'Brien LM, Eastaugh L, et al. Haemostatic changes in five patients infected with ebola virus. Viruses 2019;11(07):E647 